\section{An Army Nature Observation Scheme}

THE new Army Nature Observation Scheme has as its first object co-operation in the national wood pigeon investigation of the Edward Grey Institute at Oxford. Under this scheme, states the fifth Wood Pigeon Bulletin, recently issued, standard cards are being supplied to one of the Army Commands stationed in Britain through the unit education officers, who will periodically distribute, collect and return them. If the scheme shows promise of being a success in this Command it will be extended to others, and the printed cards have already been dispatched to the War Office. However, a naturalist in the Forces points out that, while the idea is most welcome, the difficulties are that everything depends upon the interest shown by commanding officers, whose power over the activities of their regiments is immense : many units, especially training ones, have little experience of the Army Educational Unit, and organized natural history work depends upon freedom from evening and week-end fatigues, while the largest number of results would be obtained if permission were gained to fill the cards during parade hours. For the bulk of the modern army there is little time or facility for much apart from soldiering, so technical is modern war.

The Bulletin contains interesting examinations of the sexual organs of Scottish and English wood pigeons which suggest that Seottish males develop their gonads earlier than English ones: there is the same trend among the female birds, but English birds take longer to 'catch up'. In southern England, the winter field counts suggested a low and stable population in the western portion, but quite different conditions in the middle portion with a high popula. tion, reaching its peak in January, while the eastern section, on a migration route from the Continent, had its peak figures in November, falling to a low figure in February. Counts from Scotland suggested a peak in December, whereas from England they suggested January as the peak. In Scotland the fall after the December peak was rapid, so heavy as to imply an outward movement, leaving what may be a bare resident population. In England, the January numbers suggest a sudden influx of birds.

\section{War and Medicine}

THE February issue of the Journal of Laboratory and Clinical Medicine contains an interesting article on war and medicine by Dr. Henry E. Sigerist, professor of the history of medicine at Johns Hopkins University. He remarks at the outset that the contribution of war to medicine is first of all negative. Not only are many of the élite of a nation killed or crippled, but also the civilian population are liable to be affected by famine and pestilence. On the other hand, war is a stimulus to medicine both technically and socially, as it provides opportunities for experimenting on a tremendous scale such as would never be available in time of peace. This applies particularly to surgery, as was first illustrated in ancient Greece when Greek surgeons travelled with the mercenaries in the army of the Egyptian pharaoh Psammetich. War was also responsible for the erection in ancient Rome of hospitals, which were unknown in ancient Greece. War surgery was revolutionized by Ambroise Paré, who, in his work on the treatment of gunshot wounds published in 1545, showed that these wounds heal much better without the brutal treatment of pouring on them ooiling oil which destroyed so much of the tissues. The part played by John Hunter in the expedition to Belle Isle in 1761 was notable, in that the British Navy had the services not only of a surgeon but also of a man of science. Hunter gained invaluable experience on gunshot wounds, which he discussed in his great work on "Blood, Inflammation and Gunshot Wounds" published in 1794 .

The introduction of general anæsthesia in 1846 and of antisepsis in 1867 helped to save many thousands of lives. The work of Florence Nightingale during the Crimean War of 1853-56 was the beginning of modern nursing, just as the battle of Solferino in 1859 was the starting point of the Red Cross, due to the work of the Swiss banker Henri Dunant. The value of vaccination was conclusively shown in the FrancoPrussian War of 1870-71; in the German army, where most of the soldiers were vaccinated or revaccinated, there were 4,800 cases of small-pox with 278 deaths, whereas among unvaccinated French people there were 14,000 cases with 2,000 deaths. The War of 1914-18 demonstrated the importance of protecting the workers' health, and industrial medicine led to the establishment of ministries of health in various countries. In conclusion, Dr. Sigerist states that though the present War will undoubtedly stimulate medical science, its social effects will be much more strongly felt.

\section{Cancer Control in the United States}

IN a recent paper (Public Health Rep., 57, 1613; 1942), Dr. A. Scheele describes the present cancer control activities, conducted by thirty-nine health departments and three cancer commissions in the forty-eight States and the Territory of Hawaii. The known expenditure for programmes amounted to about 1,280,000 dollars during the fiscal year ending June 30,1941 . The activities consisted of lay and professional education, provision of diagnostic and treatment facilities, and research, primarily statistical. Interest in cancer control in the United States has rapidly increased during the last few years, and most of the new programmes have developed since 1930. It seems probable that real gains in the campaign against cancer will come through improvement and extension of current programmes. Later it is hoped that the campaign will become primarily preventive rather than curative.

\section{Public Health in Chile}

THE January issue of the Boletin de la Oficina Sanitaria Panamericana contains an account of the state of public health in Chile by Dr. Juan Antonio Rlos, president of the Republic. With the exception of an outbreak of cerebro-spinal fever in Santiago and Valparaiso which has been successfully combated, there has been no recent epidemic. Typhus is no longer a menáce, and cases of typhoid fever have been decreased by mass inoculation and other measures. An efficient control of drinking water is being carried out. The various mother and child welfare services have been grouped under a Technical Advisory Division, the functions of which have been co-ordinated with those of social security and private institutions. An eye clinic and one for skin and venereal diseases have been completed. Five institutions deal with industrial accidents. 